\title{
Stress relaxation of wood-polymer composites of savewood
}

\author{
Andrey Askadskii ${ }^{1,2}$, Tatyana Matseevich ${ }^{1, *}$ and O.A. Gorbacheva ${ }^{1}$ \\ ${ }^{1}$ Moscow State University of Civil Engineering, Yaroslavskoe shosse, 26, Moscow, 129337, Russia \\ ${ }^{2}$ A.N. Nesmeyanov Institute of Organoelement Compounds of Russian Academy of Sciences, \\ Vavilova St. 28, Moscow, 119991, Russia
}

\begin{abstract}
Experiments on stress relaxation on the samples representing fragments of terraced boards have been carried out. Matrix polymer is polyvinyl chloride (PVC). The combined wood filler, which is a mixture of wood flour and chalk, has been used. Measurements conducted at different permanent deformations of compression from 2 to $5 \%$ and temperatures from 20 to $70^{\circ} \mathrm{C}$. Found that under all conditions the relative relaxation takes small values, indicating the long-term conservation of the mechanical workability of the products. Nonlinear mechanical behavior is evident already at $3 \%$ strain. At temperatures from 20 to $35^{\circ} \mathrm{C}$ relaxation processes take place almost identically, without reduction in initial and final stress. At temperatures of 50 and $70^{\circ} \mathrm{C}$ both stresses are reduced. The master curve is plotted, which allows prediction the mechanical behavior for a long time.
\end{abstract}

\section{Introduction}

As you know, the main disadvantage of terrace boards is their high water absorption. Because of the materials of the decking boards often are operated in conditions of exposure to external environment, they are exposed to rain, ice and sea water (floors in swimming pools), etc. In order to reduce water absorption into the composition is used to get the decking boards, add mineral filler. As such a filler is used, for example, $\mathrm{CaCO}_{3}$ (chalk). In the work [1] it was shown that for such wood-mineral composites water absorption is reduced several times. At the same time, the standard mechanical properties (modulus of elasticity and strength) also are increased. However, an objective assessment of the mechanical performance of polymer materials and composites requires relaxation measurements. In particular, it is necessary to carry out experiments on stress relaxation measured at different temperatures and strains. In this regard, this work is devoted to such experiments on samples of decking produced by the domestic company Savewood. Polyvinyl chloride (PVC) is used as a matrix polymer in the compositions, and wood flour in combination with chalk in a weight ratio of 60/40 is used as a combined filler.

Stress relaxation curves are experimentally recorded in tensile or compression tests at a constant strain $\varepsilon_{0}$ of the sample. In the literature there is a limited number of works devoted

\footnotetext{
* Corresponding author: MatseevichTA@mgsu.ru
} 
to stress relaxation. Among them we note the works [2-8]. Conclusions in Sections 5 and 6 complete the paper.

\section{Experimental part}

The experiments were performed to measure the curves of stress relaxation in compression on samples of dimensions $4 \times 4 \times 6.5 \mathrm{~mm}$ cut from the experimental decks at presence of the combined filler. The combined filler in its composition contained $\mathrm{CaCO}_{3}$ and wood flour. Measurements were carried out on a modified device for micromechanical tests (INEOS RAS). Approximation of stress relaxation curves was performed using a specially written computer program.

Stress relaxation curves were approximated by the Boltzmann-Volterra equation.

$$
\sigma=\sigma_{0}\left[1-\int_{0}^{t} T(\tau) d \tau\right]
$$

where $\sigma$ is the relaxing stress, $\sigma_{0}$ is the initial stress that develops at the end of the "instantaneous" deformation task, $T(\tau)$ is the memory function, $\tau$ is the current time that runs from 0 to $t, t$ is the final time.

To approximate the stress relaxation curves, we used relaxation memory functions proposed in [9-11]. The main idea of this approach is that the stress relaxation process occurs as a result of the interaction and diffusion of kinetic units, called relaxers.

The relaxation memory function includes the magnitude $\alpha$, depending on time. Change $\alpha$ over time $\tau$ may be due to two reasons: interaction of relaxers with their transition into non-relaxers and diffusion of kinetic units. If the relaxation process is limited by the rate of interaction of the relaxers, the memory function $T_{1}(\tau)$ acts. According to [9-11], the memory function $T_{1}(\tau)$ is as follows:

$$
T_{1}(\tau)=-\frac{S_{0}}{k_{B} m_{1}} \cdot \frac{1}{\left[\alpha-\alpha_{0}\right] \ln \left[\alpha-\alpha_{0}\right]+\left[1-\alpha+\alpha_{0}\right] \ln \left[1-\alpha+\alpha_{0}\right]}-\frac{1}{\ln 0,5},
$$

where $\alpha_{0}=10^{-10}$.

The value of $\alpha$ is determined by the ratio

$$
\alpha=\frac{c}{c_{0}}=\frac{1}{\left(1+k^{*} \tau / \beta\right)^{\beta}}
$$

where $k^{*}=k c_{0}{ }^{n-1}, \beta=\frac{1}{n-1}, n$ is the order of the reaction of the relaxers, $c_{0}$ is the initial concentration of the relaxers of any type, $c$ is the current concentration, $k$ is the reaction rate constant, $S_{0}$ is the initial entropy of the system (sample), $k_{B}$ is the Boltzmann constant, $m_{1}$ is the number of relaxers in the sample.

If the relaxation process is limited by the rate of diffusion of the relaxers, the memory function $T_{2}(\tau)$ is as follows:

$$
T_{2}(\tau)=-\frac{S_{0}}{k_{B} m_{2}} \cdot\left[\frac{1}{a \tau^{\gamma} \ln a \tau^{\gamma}+\left(1-a \tau^{\gamma}\right) \ln \left(1-a \tau^{\gamma}\right)}-\frac{1}{\ln 0,5}\right],
$$

where $\gamma=a / 2,0<b<1, a$ is the constant.

The memory function (4) contains three parameters: $A=\frac{S_{0}}{k_{B} m}, a$ and $\gamma$. It is a function with a weak singularity at $\tau=0$. 
For the approximation of relaxation curves in the nonlinear domain of mechanical behavior we will use the memory function $T_{1}(\tau)$. The rate constant of interaction of kinetic units is written as the ratio [6-8]:

$$
k^{*}=k_{0}^{*} \exp \left(-\frac{\Delta U_{0}-\delta \sigma_{r}}{R T}\right)=k_{0}^{*} \exp \left(-\frac{\Delta U_{0}-\delta E_{r} \varepsilon_{0}}{R T}\right),
$$

where $E_{r}$ is the relaxation modulus; $\Delta U_{0}$ is the initial energy of the interaction of often; $\sigma_{r}$ is the relaxing stress; $\varepsilon_{0}$ is the constant deformation, $\delta$ is the fluctuation volume, which is an elementary act of the interaction of relaxers; $k_{0}^{*}$ is the pre-exponential factor; $R$ is the universal gas constant, $T$ is the absolute temperature.

As an example, Figure 1 shows the accuracy of approximation of stress relaxation curves at deformation of $3 \%$ using the Boltzmann equation and $T_{1}(\tau)$ and $T_{2}(\tau)$ memory functions.

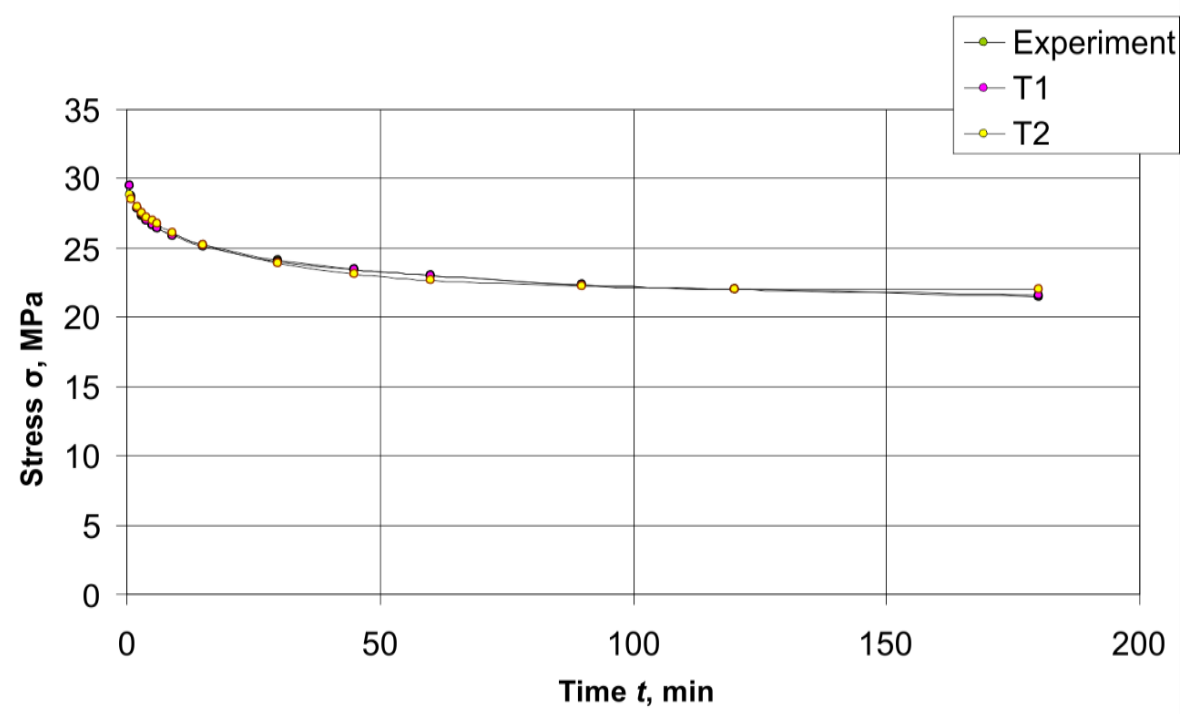

Fig. 1. Approximation of the stress relaxation curve at $20^{\circ} \mathrm{C}$; strain $\varepsilon_{0}=3 \%$, sample No. 3, containing $40 \% \mathrm{CaCO}_{3}$ and $60 \%$ wood flour.

In all cases, the approximation is most accurately carried out using the $T_{1}(\tau)$ memory function, as can be seen from the figure and table 1 . The correlation coefficient when using the $T_{1}(\tau)$ memory function is close to 1 and slightly exceeds the correlation coefficient, which is obtained using the $T_{2}(\tau)$ memory function.

Table 1. The results of the approximation of the stress relaxation curves of sample No. 3 with a deformation of $3 \%$ and different temperatures.

\begin{tabular}{|c|c|c|c|c|c|c|c|c|}
\hline \multicolumn{7}{|c|}{ Memory function $T_{1}(\tau)$} & \multicolumn{2}{|c|}{$\begin{array}{l}\text { Experimental } \\
\text { values }\end{array}$} \\
\hline $\begin{array}{l}\text { Temperature } \\
{ }^{\circ} \mathrm{C}\end{array}$ & $\begin{array}{c}k, \\
\min ^{-1}\end{array}$ & $r$ & $A, \mathrm{~J} \cdot \mathrm{mol} / \mathrm{m}^{3}$ & $n$ & $\begin{array}{c}\sigma_{0}, \\
\mathrm{MPa}\end{array}$ & $\begin{array}{l}\sigma_{\infty} \\
\mathrm{MPa}\end{array}$ & $\begin{array}{l}\sigma_{0.5}, \\
\mathrm{MPa}\end{array}$ & $\begin{array}{l}\sigma_{180}, \\
\mathrm{MPa}\end{array}$ \\
\hline 20 & 0.01 & 0.997 & $1.96 \cdot 10^{6}$ & 6.0 & 61.70 & 31.23 & 46.45 & 31.82 \\
\hline 35 & 0.01 & 0.999 & $2.30 \cdot 10^{6}$ & 6.0 & 61.51 & 26.96 & 43.98 & 28.05 \\
\hline 50 & 0.01 & 0.997 & $1.74 \cdot 10^{6}$ & 6.0 & 48.44 & 23.05 & 30.88 & 19.04 \\
\hline 70 & 0.01 & 0.996 & $1.77 \cdot 10^{6}$ & 6.0 & 42.08 & 14.92 & 28.60 & 15.43 \\
\hline
\end{tabular}




\begin{tabular}{|c|c|c|c|c|c|c|c|c|}
\hline \multicolumn{7}{|c|}{ Memory function $T_{2}(\tau)$} & \multicolumn{2}{|c|}{$\begin{array}{c}\text { Experimental } \\
\text { values }\end{array}$} \\
\hline $\begin{array}{l}\text { Temperature } \\
{ }^{\circ} \mathrm{C}\end{array}$ & $\gamma$, & $r$ & $\begin{array}{c}A, \\
\mathrm{~J} \cdot \mathrm{mol} / \mathrm{m}^{3}\end{array}$ & $a$ & $\begin{array}{l}\sigma_{0} \\
\mathrm{MPa}\end{array}$ & $\begin{array}{l}\sigma_{\infty}, \\
\mathrm{MPa}\end{array}$ & $\begin{array}{l}\sigma_{0.5} \\
\mathrm{MPa}\end{array}$ & $\begin{array}{l}\sigma_{180} \\
\mathrm{MPa}\end{array}$ \\
\hline 20 & 0.5 & 0.973 & $3.51 \cdot 10^{6}$ & 0.0403 & 46.28 & 32.89 & 46.45 & 31.82 \\
\hline 35 & 0.5 & 0.983 & $3.50 \cdot 10^{6}$ & 0.0403 & 35.13 & 28.82 & 43.98 & 28.05 \\
\hline 50 & 0.5 & 0.994 & $2.39 \cdot 10^{6}$ & 0.0403 & 31.62 & 19.61 & 30.88 & 19.04 \\
\hline 70 & 0.5 & 0.970 & $2.61 \cdot 10^{6}$ & 0.0403 & 28.33 & 16.41 & 28.60 & 15.43 \\
\hline
\end{tabular}

Let us analyze the parameters of relaxation processes obtained using the $T_{1}(\tau)$ memory function. Table 1 shows that the rate constant of the interaction of relaxers $k$ for each strain is $0.01 \mathrm{~min}^{-1}$. The value of $A$, which characterizes the number of inhomogeneities in the material, is decreased with increasing strain up to $4 \%$, and then remains almost the same. The reaction order $n$ decreases with increasing strain.

To analyze the nonlinear mechanical behavior of materials at different strains, the dependences of the relaxing module on time at different strains were constructed (Figure 4). Sample No. 1 is a standard sample obtained by Savewood, containing PVC as a matrix polymer. Sample No. 3 is a material containing a combined filler consisting of a mixture of chalk and wood flour in a 40/60 ratio. From figure 2 it is clearly seen that with increasing strain, the elastic modulus significantly decreases throughout the relaxation curve. This indicates that the nonlinear behavior begins already with a deformation of $3 \%$, and with deformations of 4 and $5 \%$, this nonlinearity increases.

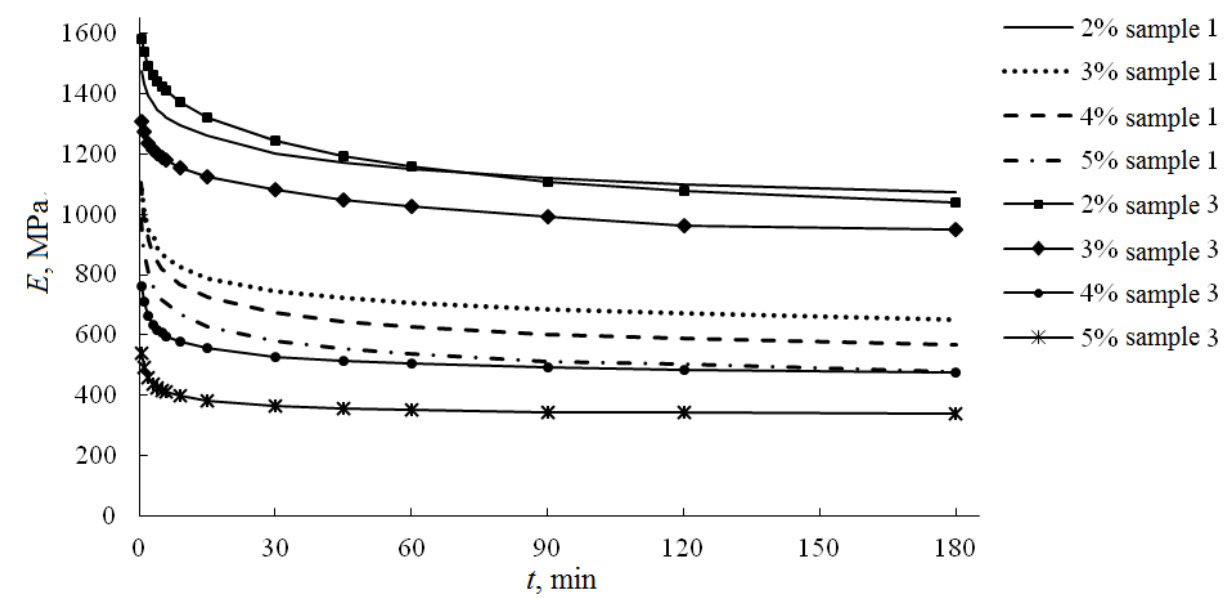

Fig. 2. Dependence of the relaxing modulus on time at various strains for samples 1 and 3.

Now analyze the effect of temperature. From figure 3 it can be seen that for sample No. 3 , the stress relaxation curves at a constant strain of $3 \%$ practically do not change with increasing temperature from 20 to $35^{\circ} \mathrm{C}$. Then, as the temperature rises to 50 and $70^{\circ} \mathrm{C}$, the stress relaxation curves shift toward lower mechanical stress. 


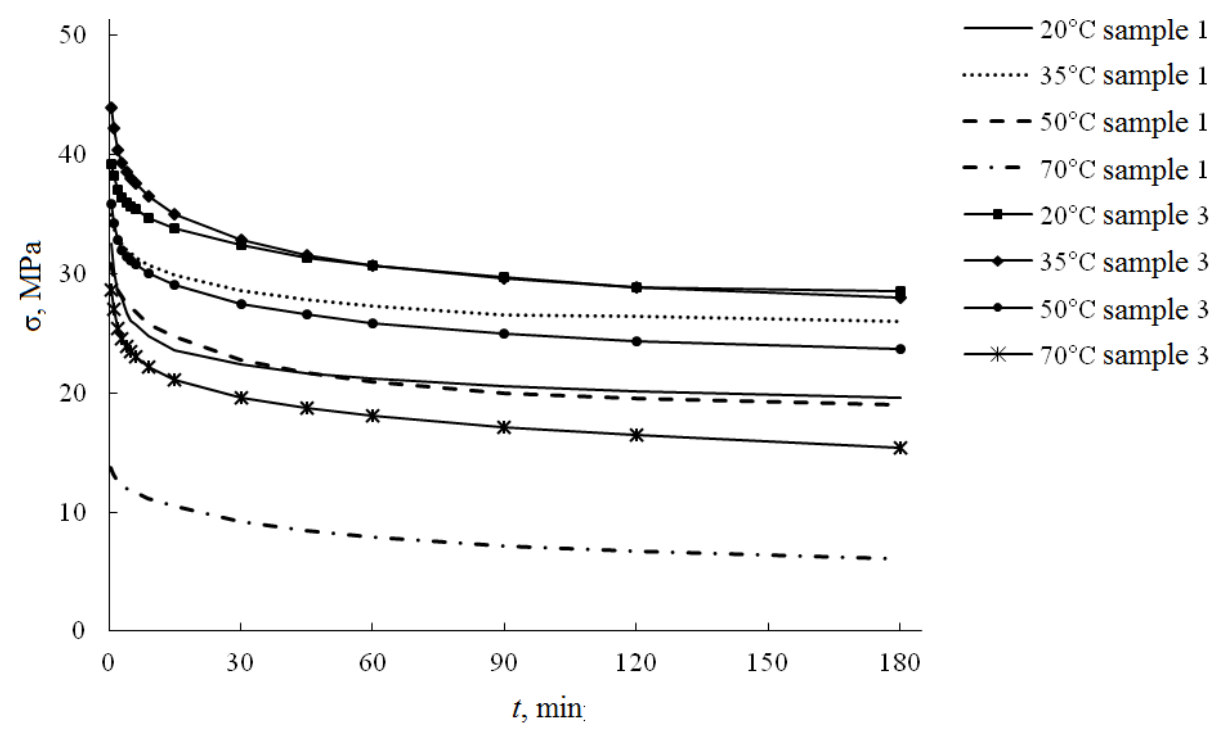

Fig. 3. Stress relaxation curves at different temperatures and deformation of $3 \%$.

For a more visual representation in Figure 4 shows the dependence of stress $\sigma_{0.5}$, which develops in $0.5 \mathrm{~min}$, on temperature

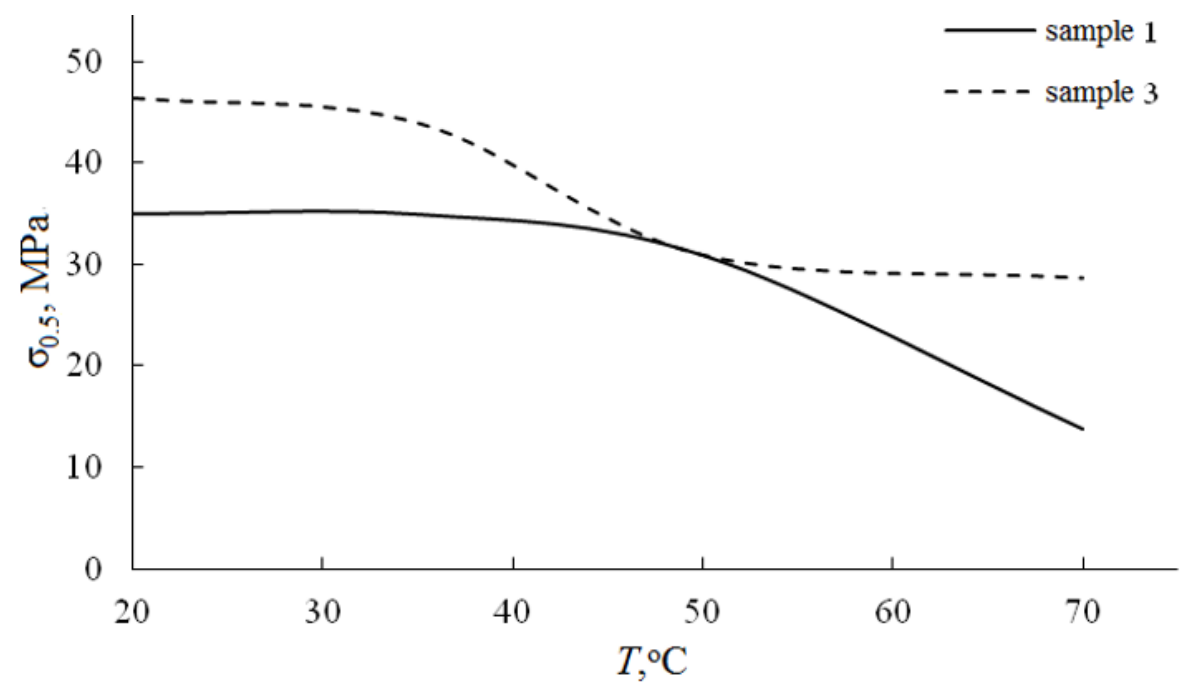

Fig. 4. Dependence of the stress $\sigma_{0}$ on temperature.

It is clearly seen that this characteristic practically does not change with an increase in temperature from 20 to $35^{\circ} \mathrm{C}$, then with an increase in temperature to $50^{\circ} \mathrm{C}$, they fall sharply, and then decrease slightly.

According to the results of measuring stress relaxation at different temperatures, using a special computer program, a master curve for sample No. 3 was constructed (Figure 5). The same figure shows the master curve for the standard sample No. 1. 


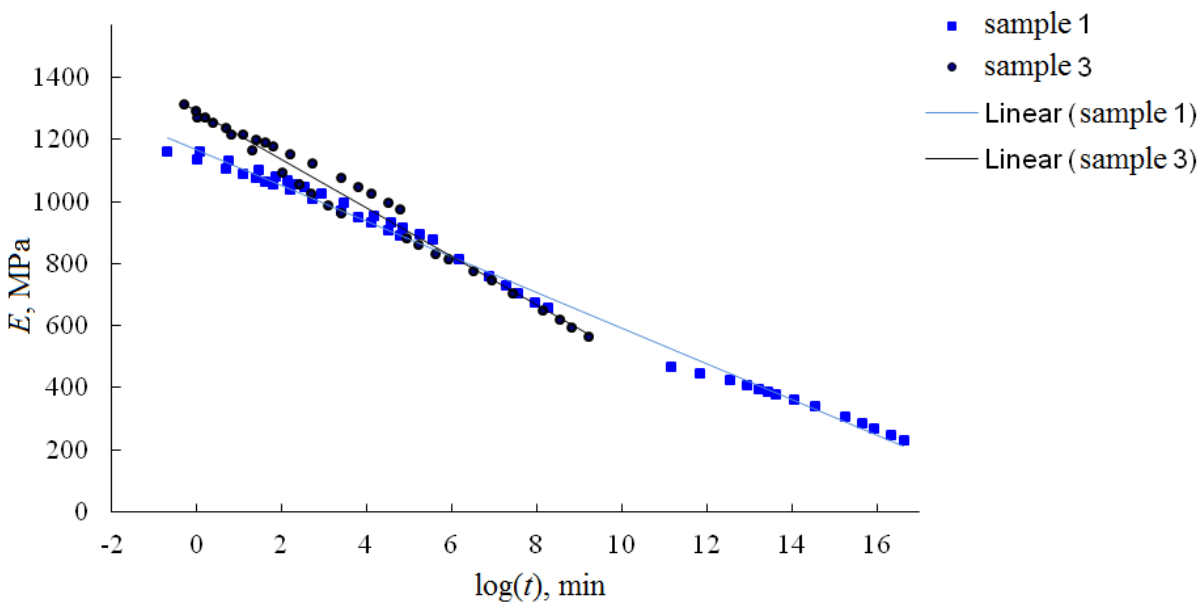

Fig. 5. Master curves for samples 1 and 3 (graphs are based on the results of the calculated data of the program, a trend line is drawn).

The data in Figure 5 shows that in the time interval from $\log t=-0.5$ to $\log t=6$, the master curve for sample No. 3 is higher than for the standard sample No. 1. At higher times, the master curves almost coincide. Therefore, a partial replacement of wood filler for mineral leads not only to a decrease in water absorption, but also to an increase in relaxing stresses, which in turn indicates an increase in the long-term mechanical performance of the material.

Let us now consider the results of the analysis of the linear and nonlinear relaxation behavior of sample No. 3. Comparisons of the relaxation modulus curves in pairs with deformations of 2 and $3 \%, 2$ and $4 \%, 2$ and $5 \%$ lead to $\delta$ values of $0 \AA^{3}, 5500 \AA^{3}$ and 6300 $\AA^{3}$, respectively. In this case, the correlation coefficient will increase to 0.999 . Thus, the nonlinear mechanical behavior is observed already at a strain of $2 \%$.

\section{Conclusion}

The introduction of mineral filler into the composition of wood-polymer composites leads not only to a decrease in water absorption, but also to an increase in relaxing stresses. This contributes to increasing the resource mechanical performance of building structures. Therefore, it is possible to recommend such a technological method for improving the quality of materials and products intended for work in the conditions of external environmental influences.

\section{References}

1. A. A. Askadskii, T. A. Matseevich, V. I. Kondrashchenko, Construction Materials, 3 (2019)

2. P. A. Moroz, Al. A. Askadskiy, T. A. Matseyevich, E. V. Solovyova, A. A. Askadskiy, Plasticheskie massy, 9-10, 56-61 (2017)

3. T. A. Matseevich, A. A. Askadskii, Stroitel'stvo: nauka i obrazovanie, 7(3), 48-59 (2017)

4. A. A. Askadskii, K. S. Piminova, A. V. Matseevich, Construction Materials, 6, 45-52 (2018)

5. T. A. Matseevich, A. A. Askadskii, Construction Materials, 1-2, 101-105 (2017)

6. T. Matseevich, E3S Web of Conferences, 33, 02075 (2018) 
7. T. Matseevich, A. Askadskii, IOP Conference Series: Materials Science and Engineering, 365(4), 042010 (2018)

8. A. Askadskii, T. Matseevich, A. Matseevich, MATEC Web of Conferences, 251, 01043 (2018)

9. A. A. Askadskii, Computational Materials Science of Polymers (Cambridge International Science Publishing, Cambridge, 2003)

10. A. A. Askadskii, A. R. Khokhlov, Introduction into physico-chemistry of polymers (Nauchnyi Mir, Moscow, 2009)

11. A. A. Askadskii, M. N. Popova, V. I. Kondrashchenko, Physico-chemistry of polymeric materials and methods of their investigation (ASV, Moscow, 2015) 